\title{
Feasibility simulation of aseismic structure design for long-span bridges
}

https://doi.org/10.1515/phys-2018-0131

Received October 15, 2018; accepted November 14, 2018

\begin{abstract}
In the traditional finite element analysis method, when simulating the feasibility of aseismic structure design of long-span bridges, only finite element analysis is carried out on the bridge structure without considering the aseismic situation of the aseismic structure of the bridge under different schemes, which leads to onesidedness of the simulation results. Therefore, a new simulation method for the feasibility study of seismic design of long-span bridges is proposed in this paper. 5 seismic isolation schemes for long-span bridge structures are designed. The lock-up devices and liquid viscous dampers are deployed in bridge structure. Numerical simulation of bridge structure is carried out by establishing calculation model and improved hierarchical Kerr spring model. The responses of long-span bridges under seismic loading for 5 seismic isolation schemes are analyzed. On this basis, the seismic performance of long-span bridges is tested by using the multi-point excitation motion equation, the response power spectrum and the structural dynamic reliability analysis based on the first transcendental failure criterion. Experimental results show that all the five seismic isolation schemes are feasible, and the seismic effect of the schemes 4 and 5 is the strongest. The maximum horizontal thrust of pier top is $6.27 \mathrm{E}+062,0.50 \mathrm{E}+07$ and $6.00 \mathrm{E}+06$, $2.78 \mathrm{E}+07$, respectively. The proposed method can be used to simulate the seismic response of long-span bridges.
\end{abstract}

Keywords: Long-span bridges, seismic design, structural design, simulation, computational model, equation of motion.

PACS: 66.20.Cy, 46.70.De, 47.27.eb

\footnotetext{
*Corresponding Author: Li Lai: Department of Road and Bridge Engineering, Jiangxi Vocational and Technical College of Communication, Nanchang, 330013 China, E-mail: laili19920405@163.com
}

\section{Introduction}

Earthquake is a natural disaster that seriously endangers mankind. Several major earthquakes occurred in cities at the end of the last century, such as the 1971 San Fernando earthquake in the United States, the 1976 Tangshan earthquake in China, the 1989 Loma Prieta earthquake in the United States, the 1994 Northridge earthquake in the United States, the 1995 Osaka-Shenzhen earthquake in Japan, and the 1999 Chi-Chi earthquake in Taiwan. As the bridge project has been severely damaged, the lifeline of traffic in the earthquake area has been cut off, the disaster relief work is difficult to carry out, and the secondary disasters have been aggravated, resulting in huge economic losses [1]. Typical bridge seismic damage can be divided into the following categories: foundation damage caused by sand liquefaction, foundation subsidence, bank slope sliding or cracking [2]; seismic damage caused by improper bridge structure, construction or connection measures; damage caused by inadequate seismic resistance (strength and ductility) of bridge piers themselves; seismic damage caused by inconsistent ground motions (spatial variability of ground motion field) at various supporting points of the bridge [3]. The seismic design of long-span bridges has attracted more and more attention from governments. Some new viewpoints and new aseismic technologies are proposed for aseismic structure design.

The seismic design of long-span bridges is changing from traditional deterministic methods to probabilistic methods, from the fixed value concept which neglected the randomness of load and structure resistance in the past to the non-fixed value concept which reasonably took into account its randomness, and from the safety factor determined by experience to the reliability index quantitatively given by probability theory in a certain reference period [4]. The significant change in the design method of this aseismic structure is closely related to the research work carried out by scholars at home and abroad in the field of reliability over the years. In the 1940s, foreign scholars first studied the difference between structural dynamic response and a fixed boundary. The mathematical expression of the number of intersections and their expec- 
tations in a certain period of time is given, which lays a foundation for the dynamic reliability theory based on the first transcendental failure principle [5]. Since then, the basic theory of structural dynamic reliability has been developed rapidly, and more attempts have been made in the practical application of bridge seismic engineering. Some scholars refer to the experimental and analytical work of foreign universities, and define the failure probability as the displacement ductility capability probability of piers not less than the displacement ductility requirement under earthquake protection level. Reliability evaluation of highway bridge piers under random seismic loading is carried out [6]. In the literature [7],the function design of bridge structure is proposed, and the evaluation standards of aseismic structure and reliability of long-span bridges are studied. However, the computational model is not set up for numerical simulation, and its application is not high. In the literature [8], a probabilistic statistical method for seismic risk assessment of bridge structures is proposed. Earthquake excitation is not considered in the structural dynamic reliability analysis. The inspection of bridge's aseismic structure is not comprehensive. In the literature [9], the application of primary reliability theory to seismic reliability analysis of long-span bridges is presented. Multi-point excitation motion equation and response power spectrum are not constructed. This method can only be applied to continuous girder bridge system.

The power spectrum analysis of structural response is a key link in the reliability analysis of long-span bridges. Due to the complexity of the calculation method of random vibration spectrum, a very simplified model is often used to analyze the seismic performance of long-span bridges [10]. Therefore, we need to consider the spatial variation effect of ground motion, that is, multi-point nonuniform random excitation. Many famous scholars have made an in-depth study of this kind of problem. It is generally believed that the random vibration spectrum is an effective method for seismic analysis, but it is still difficult to deal with the difficulties in concrete calculation. This bottleneck greatly restricts the in-depth study and engineering application of the seismic reliability theory of long-span bridges. Structural response power spectrum is an efficient algorithm for linear random vibration analysis, and it can deal with the spatial effect of ground motion conveniently. In this paper, random seismic response calculation of long-span bridge structure is carried out by establishing calculation model and improved layered Winkler spring model. On this basis, the structural response power spectrum calculation and dynamic reliability analysis are carried out. A useful exploration is made for the feasibility simulation of the seismic design of long-span bridges.

\section{Feasibility simulation of aseismic structure design for long span bridges}

\subsection{Seismic isolation design schemes for long-span bridge structures}

The traditional aseismic structural design scheme of longspan bridges is that No. 3 pier of the bridge adopts double thin-walled pier rigid joint to form T-type rigid frame system, and the other five piers adopt basin rubber bearings. This design results in low seismic resistance of longspan bridges [11]. In order to reduce the damage degree of long-span bridges under strong earthquake load and reduce the difficulty of pier design, five seismic isolation design schemes are proposed in this paper.

Scheme 1: Double thin-walled pier rigid junction is adopted for the No. 3 pier of the bridge, and the remaining 5 piers are equipped with lock-up devices. One lock-up device is used on both sides of each thin-walled pier.

Scheme 2: Double thin-walled pier rigid junction is adopted for the No. 3 pier of the bridge, while the other 5 piers adopt liquid viscous dampers. 1 liquid viscous damper is used on both sides of each thinwalled pier. Damping coefficient of liquid damper is $c=1 e 6\left(\mathrm{~N} / \mathrm{m} \cdot \mathrm{s}^{2}\right)$ and each thin-walled pier is $c=$ $2 e 6\left(\mathrm{~N} / \mathrm{m} \cdot \mathrm{s}^{2}\right)$.

Scheme 3: Double thin-walled pier rigid junction is adopted for the no. 3 pier of the bridge, while the other 5 piers adopt liquid viscous dampers. 1 liquid viscous damper is used on both sides of each thinwalled pier. Damping coefficient of liquid damper is $c=2 e 6\left(\mathrm{~N} / \mathrm{m} \cdot \mathrm{s}^{2}\right)$ and each thin-walled pier is $c=$ $4 e 6\left(\mathrm{~N} / \mathrm{m} \cdot \mathrm{s}^{2}\right)$.

Scheme 4: Double thin-walled pier rigid junction is adopted for the no. 3 pier of the bridge, lock-up device is installed for no. 4 pier, and liquid viscous damper is used for the other four piers. 1 liquid viscous damper is used on both sides of each thin-walled pier. Damping coefficient of liquid damper is $c=1 e 6\left(\mathrm{~N} / \mathrm{m} \cdot \mathrm{s}^{2}\right)$ and each thin-walled pier is $c=2 e 6\left(\mathrm{~N} / \mathrm{m} \cdot \mathrm{s}^{2}\right)$.

Scheme 5: Double thin-walled pier rigid junction is adopted for the no. 3 pier of the bridge, lock-up device is installed for no. 4 pier, and liquid viscous damper is used for the other four piers. 1 liquid viscous damper is used on 
both sides of each thin-walled pier. Damping coefficient of liquid damper is $c=2 e 6\left(\mathrm{~N} / \mathrm{m} \cdot \mathrm{s}^{2}\right)$ and each thin-walled pier is $c=4 e 6\left(\mathrm{~N} / \mathrm{m} \cdot \mathrm{s}^{2}\right)$.

\subsection{Numerical simulation method}

In order to evaluate the merits and demerits of the five schemes, the response of long-span bridges under seismic loads is analyzed by numerical simulation and ANSYS software. According to the magnitude of earthquake response, we can judge the advantages and disadvantages of aseismic schemes.

\subsection{Vibration analysis of long-span bridge structures}

Finite element dynamic calculation model is used to analyze long-span bridge structures when liquid viscous dampers are used. Vibration equation of bridge structure (including foundation) in coordinate system is given by

$$
[M]^{\cdot}\{\ddot{\delta}\}+[C]^{\cdot}\{\dot{\delta}\}+[K]^{\cdot}\{\delta\}=-F_{x} F_{y}[M]^{\cdot}[R]\left\{\ddot{\delta}_{g}\right\}
$$

where $[M],[C],[K]$, and $[R]$ are the mass matrix, damping matrix and stiffness matrix of the structure, $\{\ddot{\delta}\},\{\dot{\delta}\}$, and $\{\delta\}$ are the acceleration, velocity and displacement vector of the structure, $\left\{\ddot{\delta}_{g}\right\}$ is the seismic acceleration, $\mathrm{F}_{x}$ and $\mathrm{F}_{y}$ are the bearing pressure of bridge structure on $\mathrm{x}$ axis and y axis.

Relationship between motion and damping force of liquid viscous damper is given by

$$
\{F\}^{e}=\left[C_{d}\right]^{e}\left\{\dot{\delta}^{a}\right\} D^{e} M
$$

where $\left[C_{d}\right]$ is the damping stiffness matrix of liquid damper, $\left\{\dot{\delta}^{a}\right\} D^{e}$ is the relative velocity between two ends of damper, $\alpha$ is the velocity index, $M$ is the amplitude of damping force. Using 0.3-1.0 as the design parameter, the damper function is taken into account in the structural vibration. Then

$$
[M]^{\prime}\{\ddot{\delta}\}+[C]^{\cdot}\{\dot{\delta}\}+[K]^{\cdot}\{\delta\}+\left[C_{d}\right]\left\{\dot{\delta}^{a}\right\}_{D}=-[M]^{\cdot}[R]\left\{\ddot{\delta}_{g}\right\}
$$

When the lock-up device and liquid viscous damper are used in the long-span bridge structure, the lock-up device can be regarded as a simple speed switch in analyzing the finite element structural dynamic calculation model. When the lock-up device is used on the bridge structure, one end is located on the beam body and the other end is on the pier [12]. When the seismic load arrives, the lock-up device can constrain the horizontal displacement between



Figure 1: Schematic diagram of lock-up device

the piers. The schematic diagram of the lock-up device is shown in Figure 1.

In Figures 1a and 1b there are bridge superstructures, $c$ is pier structure, the node 2 is beam node, the node 4 is pier top node, and lock-up device is installed between 2 and 4 . The degrees of freedom of nodes 2 and 4 are coupled with vertical degrees of freedom, and they can be freely rotated. Before the unit c participates in system integration, the finite element equation in its own coordinate system can be expressed as

$$
\left[\begin{array}{l}
\mathrm{K}_{\mathrm{a}} \mathrm{K}_{\mathrm{ab}} \\
\mathrm{K}_{\mathrm{ba}} \mathrm{K}_{\mathrm{be}}
\end{array}\right]\left\{\begin{array}{c}
\delta_{\mathrm{a}} \\
\delta_{b}
\end{array}\right\}^{e}=\left\{\begin{array}{c}
P_{a} \\
P_{b}
\end{array}\right\}^{e}
$$

where $\left[\begin{array}{l}\mathrm{K}_{\mathrm{a}} \mathrm{K}_{\mathrm{ab}} \\ \mathrm{K}_{\mathrm{ba}} \mathrm{K}_{\mathrm{be}}\end{array}\right]$ is the finite element coordinates, $\delta_{\mathrm{a}}$ is the degree of freedom to be retained, $\delta_{b}$ is the degree of freedom to be condensed. $P_{a}$ and $P_{b}$ are the influence coefficient of the nodes $a$ and $b$. According to the second equation in Eq. (4),

$$
\delta_{b}=\mathrm{K}_{b}^{-1}\left(P_{b}-\mathrm{K}_{\mathrm{ba}} \delta_{a}\right)
$$

Substitute Eq. (5) into the first equation in Eq. (4), the unit equation after condensation is obtained as $K^{\star} \delta_{\text {a }}=$ $P_{a}{ }^{\star}$, where $K^{\star}=K_{a}-K_{a b} K_{b}^{-1} K_{b a}, P_{a}{ }^{\star}=P_{a}-K_{a b} K_{b}^{-1} P_{b}$. The element stiffness matrix considering the effect of lockup is adopted to integrate $K^{\star}$ into system integration. 


\subsection{Numerical simulation of long-span bridge structure}

The response of long-span bridges under seismic loads under five kinds of seismic isolation schemes is analyzed by establishing calculation model and improved layered Winkler spring model.

The long-span bridge group pile foundation can be regarded as a spatial rigid frame with rigid base plate. According to the actual force characteristics of the pier, the pile group foundation is usually simplified as a plane rigid frame along the symmetrical plane. The displacement (vertical displacement, horizontal displacement and rotation angle) of the origin of the cap coordinate is solved by the displacement method of structural mechanics, as shown in Eq. (6). The internal forces (bending moment, shear force and axial force) at the top of any pile are obtained.

$$
\left\{\begin{array}{l}
b=\frac{N}{\gamma_{b b}} \\
a=\frac{\gamma_{\beta \beta} H-\gamma_{\alpha \beta} M}{\gamma_{a a} \gamma_{\beta \beta}-\gamma^{2}{ }^{2} \beta} \\
\beta=\frac{\gamma_{a \alpha} M-\gamma_{\alpha \beta} \beta}{\gamma_{a a} \gamma_{\beta \beta}-\gamma^{2}{ }_{\alpha \beta}}
\end{array}\right.
$$

where

$$
\left\{\begin{array}{l}
\gamma_{b b}=\sum n_{i} \rho_{1} \\
\gamma_{a a}=\sum n_{i} \rho_{2} \\
\gamma_{\beta \beta}=\sum n_{i} \rho_{4}+\rho_{1} \sum n_{i} x_{i}^{2} \\
\gamma_{\alpha \beta}=\gamma_{\beta \alpha}=-\sum n_{i} \rho_{3}
\end{array}\right.
$$

where $\gamma_{b b}, \gamma_{a a}, \gamma_{\beta \beta}$, and $\gamma_{\alpha \beta}$ are the stiffness coefficient of bridge pile top, $\rho_{1}$ is the axial force at the top of the component when the displacement of the underside of the pile cap occurs along the axis of the member, $\rho_{2}$ is the transverse force at the top of the component when the lateral displacement of the underside of the cap is generated along the axis of the vertical component, $\rho_{3}$ is the bending moment at the top of the component when the lateral displacement of the underside of the cap is generated along the axis of the vertical component, or the lateral force at the top of the component when the unit angle is generated along the bending moment of the top surface of the pile cap, and $\rho_{4}$ is the bending moment at the top surface of the bottom of the pile cap when the unit angle is generated along the bending moment of the top part of the component. $\rho_{1}$ is given by

$$
\rho_{1}=\frac{1}{\frac{\xi L}{E A}+\frac{1}{C_{0} A_{0}}}
$$

For bored friction piles, assume the lateral friction is evenly distributed, that is $\xi=0.5$,the axial load on the top of a single pile is shared by the lateral friction and the soil resistance at the bottom of the pile. Therefore, the axial force from pile below the ground gradually decreases [13].
The value of $\rho_{1}$ is related to the side friction resistance and the resistance stiffness of the soil under the pile, and affects the translation displacement $\alpha$ and rotation angle $\beta$ of the origin of the base coordinate of the pile cap, and then affects the force and deformation of the single pile group foundation. However, the layered Winkler spring model usually only focuses on the stiffness of horizontal soil spring on the side of pile, ignoring the effect of vertical stiffness $\rho_{1}$ on the top of piles. Therefore, an improved layered Kerr spring model is proposed in this paper.

The improved layered Winkler spring model indirectly considers the influence of the vertical friction and the resistance of the pile bottom soil through the equivalent area of the pile body. The section area of the pile body is adjusted according to the principle of equal axial stiffness of the pile body according to the size of $\rho_{1}$, but the moment of inertia and the length of the pile remain unchanged. The equivalent area of pile body is calculated by using Eq. (10).

Let

$$
\rho_{1}=\frac{1}{\frac{\xi L}{E A}+\frac{1}{C_{0} A_{0}}}=\frac{E A_{1}}{L}
$$

then

$$
A_{1}=\frac{L_{\rho_{1}}}{E}=\frac{L}{E\left(\frac{\xi L}{E A}+\frac{1}{C_{0} A_{0}}\right)}
$$

In Eq. (8) Eq. (10), $C_{0}$ is the vertical foundation coefficient of pile bottom, $C_{0}=m_{0} L$. If , $L=10 \mathrm{~m}$. For friction bored pile, $\xi$ is set to 0.5 . A is the sectional area of pile body, $A_{1}$ is the equivalent section area of pile body, $A_{0}$ is the stress area of foundation at pile bottom. For frictional pile with scouring lines from the ground or part of the pile side, the area spread downward to the tip of the pile according to $\varphi / 4$ ( $\varphi$ is the internal friction angle of the soil layer).

\subsection{Seismic performance test of long-span bridge structure}

The seismic performance of long-span bridge structures is tested by multi-point excitation motion equation and response power spectrum. In order to analyze seismic performance of discrete long-span bridges subjected to inhomogeneous ground motions, assume the structure has $N$ bearings. In the absolute coordinate system as the center of the earth, the equation of structural motion can be written as the following block form.

$$
\begin{aligned}
& {\left[\begin{array}{l}
M_{s s} M_{s m} \\
M_{m s} M_{m m}
\end{array}\right]\left\{\begin{array}{l}
\ddot{x}_{s} \\
\ddot{x}_{m}
\end{array}\right\}+\left[\begin{array}{l}
C_{s s} C_{s m} \\
C_{m s} C_{m m}
\end{array}\right]\left\{\begin{array}{l}
\dot{x}_{s} \\
\dot{x}_{m}
\end{array}\right\}} \\
& +\left[\begin{array}{l}
K_{s s} K_{s m} \\
K_{m s} K_{m m}
\end{array}\right]\left\{\begin{array}{l}
x_{s} \\
x_{m}
\end{array}\right\}=\left\{\begin{array}{l}
0 \\
f_{m}
\end{array}\right\}
\end{aligned}
$$


where $x_{m}$ is the forced ground displacement of support, is the displacement of all non-support nodes, $f_{m}$ is the force acting on $N$ supports by the ground. Using the discretization model obtained by lumped mass method, $M_{s m}$ and $M_{m s}$ are set to zero. The absolute displacement in Eq. (11) is decomposed into the sum of quasi-static displacement $\left\{y_{s}\right\}$ and dynamic relative displacement $y_{r}$. Then

$$
\left\{\begin{array}{l}
x_{s} \\
x_{m}
\end{array}\right\}=\left\{\begin{array}{l}
y_{s} \\
x_{m}
\end{array}\right\}+\left\{\begin{array}{l}
y_{r} \\
0
\end{array}\right\}
$$

Assume the damping force of the structure is directly proportional to the dynamic relative displacement. According to Eq. (12), the equation of motion given by Eq. (11) is expanded to

$\left[M_{s s}\right]\left\{\ddot{y}_{r}\right\}+C_{s s}\left\{\dot{y}_{r}\right\}+\left[K_{s s}\right]\left\{y_{r}\right\}=\left[M_{s s}\right]\left(\left[K_{s s}\right]^{-1}\left[K_{s m}\right]\right)\left\{\ddot{x}_{m}\right\}$

which is the general expression of the motion equation of long-span bridge structure considering the ground motion of the space change.

For long-span bridges subjected to multi-point zeromean normal stationary random earthquake excitation, the acceleration power spectrum matrix of ground motion has the following form

$$
\left[S_{\ddot{x}_{m} \ddot{x}_{m}}(\omega)\right]=\left[e^{-i \omega T}\right]^{\star}[S][R][S]\left[e^{-i \omega T}\right]
$$

where

$$
\begin{gathered}
{[S]=\operatorname{diag}\left[\sqrt{S_{\ddot{x}_{1}}(\omega)}, \sqrt{S_{\ddot{x}_{2}}(\omega)}, \ldots, \sqrt{S_{\ddot{x}_{N}}(\omega)}\right]} \\
{\left[e^{-i \omega T}\right]=\operatorname{diag}\left[\exp \left(-i \omega T_{1}\right), \exp \left(-i \omega T_{2}\right), \ldots, \exp \left(-i \omega T_{N}\right)\right]} \\
{[R]=\left[\begin{array}{l}
1 \rho_{12} \cdots \rho_{1 N} \\
\rho_{21} 1 \rho_{2 N} \\
\vdots \\
\rho_{N 1} \rho_{N 2} \cdots 1
\end{array}\right]}
\end{gathered}
$$

where $S_{\ddot{x}_{K}}(\omega)$ is the ground acceleration power spectral density function at the site $\mathrm{K}$. Assume the seismic wave reaches the reference point at $\mathrm{t}=0, T_{N}$ is the time when the earthquake reaches $N$ point, $\rho_{K L}$ is the coherence coefficient of the point $K$ and the point $L,\left[e^{-i \omega T}\right]$ is the aseismic function of structure. Eq. (15) (17) respectively reflects the local site effect, traveling wave effect and partial coherence effect of spatial variation of ground motion of long-span bridges under earthquakes.

The power spectrum matrix $\left[S_{\ddot{x}_{m} \ddot{x}_{m}}(\omega)\right]$ is a nonnegative definite Hermitian matrix and the coherence coeffcient matrix $[R]$ is a nonnegative definite real symmetric matrix. If the rank of the $[R]$ matrix is $\mathrm{r}(\mathrm{r} \leq \mathrm{N})$, the following decomposition can be performed.

$$
[R]=[Q][Q]^{T}
$$

where $[\mathrm{Q}]$ is the real $\mathrm{N} \times \mathrm{r}$ matrix. Substitute Eq. (18) into Eq. (14),

$$
\left[S_{\ddot{x}_{m} \ddot{x}_{m}}(\omega)\right]=[B]^{\star}[B]^{T}
$$

where

$$
[B]=\left[e^{-i \omega T}\right][S][Q]
$$

A virtual excitation acceleration vector is constructed by using every column vector $\left\{b_{j}\right\}(j=1,2, \ldots, r)$ in [B].

$$
\{\tilde{n} \ddot{n} \not\}\}=\left\{b_{j}\right\} \exp (i \omega t)
$$

The corresponding virtual displacement vector is given by

$$
\left\{\tilde{x}_{m j}\right\}=-\left\{\ddot{\tilde{x}}_{m j}\right\} / \omega^{2}
$$

By substituting $\left\{\ddot{\tilde{x}}_{m j}\right\}$ in Eq. (22) into Eq. (13), the dynamic relative displacement $\left\{\tilde{y}_{r_{j}}\right\}$ of long-span bridge structure under the $j$-th virtual excitation is obtained. The pseudo-static displacement $\left\{\tilde{y}_{s_{j}}\right\}$ under the $j$-th virtual excitation can be obtained by ignoring all the dynamic terms in the equation of motion Eq. (11) and using Eq. (22). According to Eq. (12),the absolute displacement $\left\{\tilde{x}_{s_{j}}\right\}$ under the $j$-th virtual excitation is obtained. Then, the response power spectrum matrix of long-span bridge structures under arbitrary coherent stationary excitation is obtained. The absolute response power spectrum matrix of longspan bridge structures under $r$ independent excitations is given by

$$
\left[S_{\ddot{x}_{m} \ddot{x}_{m}}(\omega)\right]=\sum_{j=1}^{r}\left\{\tilde{x}_{S_{j}}\right\}^{*}\left\{\tilde{x}_{S_{j}}\right\}^{T}
$$

If all the elements in the coherence function matrix [R] of Eq. (17) are 1, the case is degenerated to one in which only traveling wave effect is considered. Further, if the time difference of each support movement is $T_{K}=0(k=$ $1,2, \ldots, N)$, it will become a uniform ground motion condition.

\subsection{Dynamic reliability analysis of bridge structures based on first exceeding failure criterion}

The first transcendental failure criterion is widely applied in detecting the seismic behavior of long-span bridges. It is defined that: If the dynamic response of a long-span 
bridge exceeds the critical value or safety limit for the first time (such as stress at the control point, strain, displacement and elongation of the control layer, etc.),the structure is considered to be damaged [14]. In the dynamic reliability analysis of bridge structures based on the first transcendental failure criterion, there are two commonly used methods for the dynamic reliability analysis of bridge structures, according to the probability distribution of the bridge structural response and the number of crossing boundaries.

Davenport assumes that any two time difference events that respond to stochastic processes and boundaries are independent of each other. That is, the stochastic process in the time $(0, \tau]$ is bounded by the Poisson distribution. The dynamic reliability of symmetric bilateral $D$ boundaries is given by

$$
P_{S}(b,-b)=\exp \left\{-v \tau \exp \left(-\frac{b^{2}}{2 \sigma_{y}^{2}}\right)\right\}
$$

where is the standard deviation of stochastic process $\mathrm{y}(\mathrm{t})$, $b$ is the symmetric bilateral threshold value, $v$ is the average zero crossing rate of stochastic process, and

$$
v=\frac{1}{\pi}\left(\frac{\lambda_{2}}{\lambda_{0}}\right)^{1 / 2}
$$

where $\lambda_{0}$ and $\lambda_{2}$ are power spectrum spectral moments of the stochastic process,

$$
\lambda_{k}=2 \int_{0}^{\infty} \omega^{k} S_{y y}(\omega) d \omega(k=0,2)
$$

Based on the assumption that the structural response and the number of bounded intersections occur in groups and obey the two-state Markov process, Vanmarcke proposed the formula for calculating the reliability of the bilateral D-bound of the symmetrical long-span bridge structure, which is given by

$P_{S}(b,-b)=\exp \left\{-v \tau \exp \left(-\frac{b^{2}}{2 \sigma_{y}^{2}}\right) \frac{1-\exp \left[-\sqrt{\pi / 2} q b / \sigma_{y}\right]}{1-\exp \left(-\frac{b^{2}}{2 \sigma_{y}^{2}}\right)}\right\}$

where $\mathrm{q}$ is the power spectrum bandwidth parameter

$$
q=\left(1-\frac{\lambda_{1}^{2}}{\lambda_{0} \lambda_{2}}\right)^{\frac{1}{2}}
$$

The above method of calculating reliability is only for single component under single failure mode. It is much more difficult to calculate the reliability of actual bridge structure, mainly because there may be more than one failure member, and the failure mode of the structure may be more than one form. The calculation of reliability of general structural system is to adopt an equivalent system to simulate the actual structure while considering all the corresponding failure modes [15-21]. In aseismic engineering of long-span bridges, the bridge structure itself is a complex statically indeterminate structure system. There are many failure modes, and the failure modes may not be completely correlated or independent of each other. The lower structure of bridge (pier and tower) is an important subsystem of the system, and it is also the main resistance system of bridge against earthquake. Therefore, it can be used as the main research object of bridge dynamic reliability. Assume each pier (tower) has $n$ dangerous sections (control cross section), and can be simulated by series system. The failure probability of structure is given by

$$
P_{f}=P_{f, 1} \cup P_{f, 2} \cup \cdots \cup P_{f, i} \cup \cdots \cup P_{f, n}
$$

where $P_{f, i}$ is the failure probability of the component $i$. The failure probability is calculated by multiple integrals, and the joint probability distribution function of each random variable is difficult to determine. The upper and lower limit of the failure probability is usually calculated only, which is given by

$$
\max _{i=1}^{n} P_{f, i} \leq P_{f} \leq 1-\prod_{i=1}^{n}\left(1-P_{f, i}\right)
$$

The upper bound of failure probability $P_{f}$ for a series system corresponds to the case where the failure of each component is independent of each other or there is no simultaneous failure component. The lower bound corresponds to the case where the failure of each component is completely correlated. The upper and lower limits of dynamic reliability $P_{S}$ of long-span bridge structures can be further determined by Eq. (30).

$$
\prod_{i=1}^{n} P_{S, i} \leq P_{S} \leq \min _{i=1}^{n} P_{S, i}
$$

\section{Results}

In order to evaluate the proposed five seismic isolation schemes for long-span bridges, the seismic responses of long-span bridges under five seismic schemes are analyzed by numerical simulation method and ANSYS software. According to the magnitude of earthquake response, we can judge the aseismic schemes. 


\subsection{1 Comparison of seismic response calculation results}

Due to the time-lag effect of liquid viscous damper, there is a time lag between the appearance of the most disadvantageous stress state of rigid and non-rigid piers and the appearance of the most disadvantageous stress state when using lock-up device. In data processing, the forces acting on the lock-up device and the liquid viscous damper are shown in Table $1 \sim$ Table 3 according to the total forces acting on the device on each thin-walled pier.

\subsection{Engineering example}

The deck and bridge of a long-span suspension bridge are described by three-dimensional beam elements with rigid arms, while the main cable and suspension are described by one-dimensional cable elements. The total bridge consists of 769 nodes ( 29 ground nodes), 1010 units, and 2257 degrees of freedom. The damping ratio of each mode of bridge is set to 0.01 . The first 200 order of the vibration mode are taken. The apparent wave velocity of longitudinal seismic $\mathrm{P}$ wave along the bridge deck is $3000 \mathrm{~m} / \mathrm{s}$.

Series model simulation is applied to single bridge. The proposed algorithm is used to calculate the dynamic reliability of suspension bridge A. A total of 8 sections are calculated for each of the 4 sections at the bottom of each branch of the bridge. Three cases of fortification intensity of 7,8 and 9 are calculated respectively (actual site intensity is between 7 and 8 degrees). Table 4 shows the dynamic reliability of bridge structures with uniform ground excitation. Table 5 and Table 6 show the calculation results considering traveling wave effect and partial coherence effect respectively.

\subsection{Analysis of factors affecting the equivalent area of pile in the improved layered Kerr spring model}

In order to study the influence of pile length, pile diameter and vertical foundation coefficient of pile bottom soil on the equivalent area of pile body in the improved layered Winkler spring model for long-span bridges, parametric analysis is carried out in this paper. The length of pile $\mathrm{L}$ is set to $20 \mathrm{~m}, 40 \mathrm{~m}$, and $60 \mathrm{~m}$, respectively. The pile diameter $D$ is set to $1.0 \mathrm{~m}, 1.25 \mathrm{~m}$, and $1.5 \mathrm{~m}$. The vertical foundation coefficient $\mathrm{m} 0$ of pile bottom soil is set to $1000 \mathrm{kN} / \mathrm{m} 4$, $2000 \mathrm{kN} / \mathrm{m} 4,4000 \mathrm{kN} / \mathrm{m} 4$ and $8000 \mathrm{kN} / \mathrm{m} 4$. The change of the equivalent area ratio $\eta$ of pile section with the change of $\mathrm{m} 0$, pile diameter $\mathrm{D}$ and pile length $\mathrm{L}$ is as shown in Figure 2 up to Figure 4.

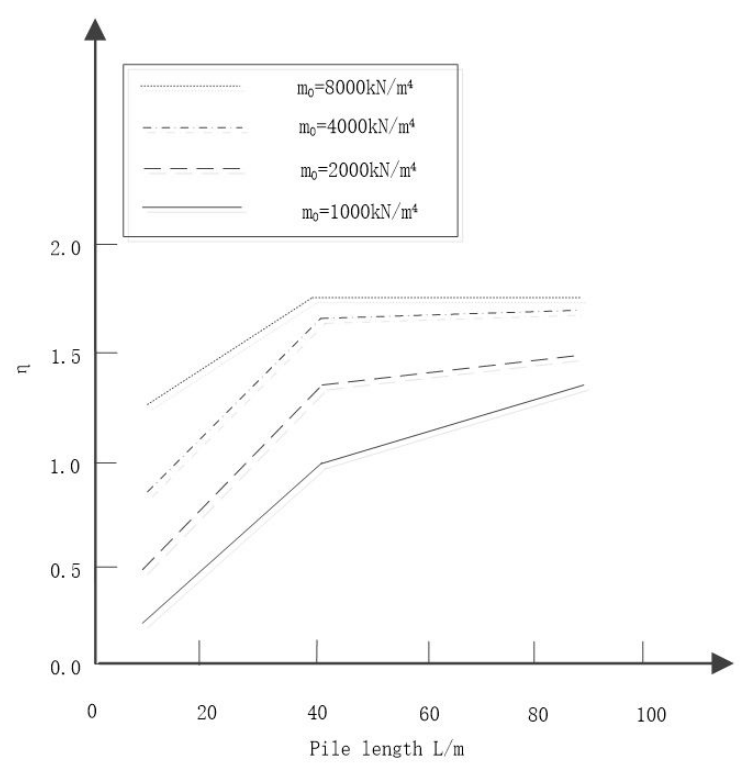

Figure 2: The change curve of $D=1.0 \mathrm{~m}$

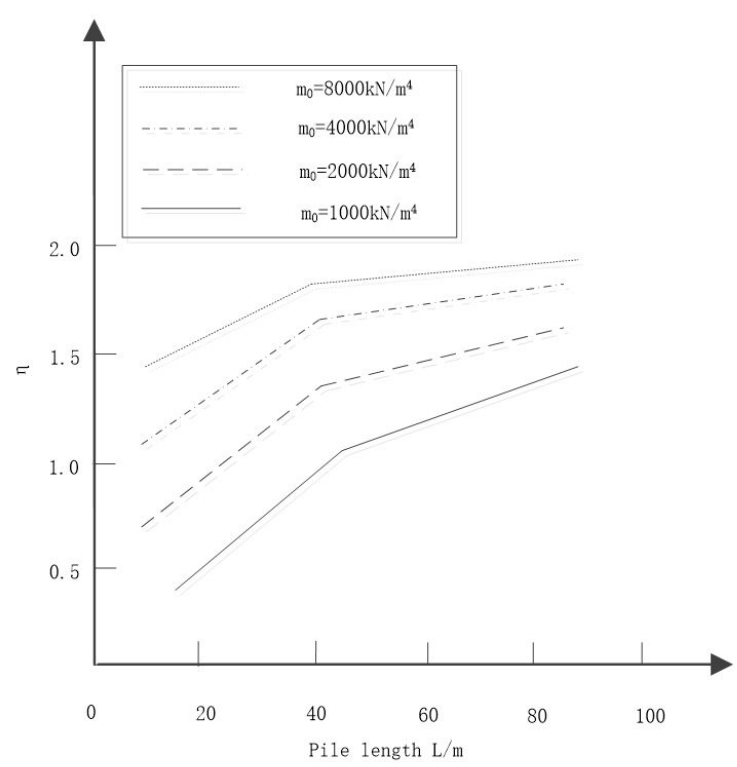

Figure 3: The change curve of $D=1.25 \mathrm{~m}$ 
Table 1: Comparison of internal forces of piers when lock-up and liquid dampers are used alone

\begin{tabular}{|c|c|c|c|c|c|c|c|}
\hline \multirow[t]{2}{*}{ Scheme number } & \multirow[t]{2}{*}{$\begin{array}{l}\text { Section } \\
\text { position }\end{array}$} & \multicolumn{3}{|c|}{$\begin{array}{l}\text { The most dangerous internal force of No. } 1 \\
\text { A pier }\end{array}$} & \multicolumn{3}{|c|}{$\begin{array}{l}\text { The most dangerous internal force of the } \\
\text { No. } 3 \text { A pier }\end{array}$} \\
\hline & & $\mathrm{Fx} / \mathrm{N}$ & $\mathrm{Fy} / \mathrm{N}$ & $\mathrm{M} / \mathrm{N} . \mathrm{m}$ & $\mathrm{Fx} / \mathrm{N}$ & $\mathrm{Fy} / \mathrm{N}$ & $\mathrm{M} / \mathrm{N} . \mathrm{m}$ \\
\hline \multirow{2}{*}{ Scheme 1} & Pier top & $3.24 \mathrm{E}+06$ & $2.40 \mathrm{E}+06$ & 99.89 & $4.97 \mathrm{E}+06$ & $4.95 \mathrm{E}+06$ & $3.22 \mathrm{E}+07$ \\
\hline & Bottom of pier & $3.61 \mathrm{E}+06$ & $2.40 \mathrm{E}+06$ & $3.93 \mathrm{E}+07$ & $5.44 \mathrm{E}+06$ & $4.96 \mathrm{E}+06$ & $3.36 \mathrm{E}+07$ \\
\hline \multirow{2}{*}{ Scheme 2} & Pier top & $7.03 E+06$ & $7.47 \mathrm{E}+05$ & 67.558 & $8.04 \mathrm{E}+06$ & $9.70 \mathrm{E}+06$ & $5.70 \mathrm{E}+00$ \\
\hline & Bottom of pier & $1.13 \mathrm{E}+06$ & $7.43 E+05$ & $1.05 \mathrm{E}+07$ & $8.26 \mathrm{E}+06$ & $9.70 \mathrm{E}+06$ & $5.20 \mathrm{E}+07$ \\
\hline \multirow{2}{*}{ Scheme 3} & Pier top & $1.17 \mathrm{E}+06$ & $9.56 \mathrm{E}+05$ & 165.96 & $7.18 \mathrm{E}+06$ & $8.51 \mathrm{E}+06$ & $4.53 \mathrm{E}+07$ \\
\hline & Bottom of pier & $1.49 \mathrm{E}+06$ & $9.52 \mathrm{E}+05$ & $1.53 \mathrm{E}+07$ & $7.40 \mathrm{E}+06$ & $8.52 \mathrm{E}+06$ & $4.66 \mathrm{E}+07$ \\
\hline \multirow[t]{2}{*}{ Traditional design } & Pier top & & & & $9.09 \mathrm{E}+06$ & $1.43 \mathrm{E}+07$ & $5.70 \mathrm{E}+07$ \\
\hline & Bottom of pier & & & & $9.33 \mathrm{E}+06$ & $1.43 E+07$ & $5.91 \mathrm{E}+07$ \\
\hline
\end{tabular}

Table 2: Internal force comparison of pier when combined lock-up and liquid dampers

\begin{tabular}{|c|c|c|c|c|c|c|c|c|c|c|}
\hline \multirow[t]{2}{*}{$\begin{array}{l}\text { Scheme } \\
\text { number }\end{array}$} & \multirow[t]{2}{*}{$\begin{array}{l}\text { Section } \\
\text { posi- } \\
\text { tion }\end{array}$} & \multicolumn{3}{|c|}{$\begin{array}{l}\text { The most dangerous internal } \\
\text { force of No. } 1 \mathrm{~A} \text { pier }\end{array}$} & \multicolumn{3}{|c|}{$\begin{array}{l}\text { The most dangerous internal } \\
\text { force of the No. } 3 \text { A pier }\end{array}$} & \multicolumn{3}{|c|}{$\begin{array}{l}\text { The most dangerous internal } \\
\text { force of No. } 4 \text { A pier using } \\
\text { lock-up }\end{array}$} \\
\hline & & $\mathrm{Fx} / \mathrm{N}$ & $\mathrm{Fy} / \mathrm{N}$ & $\mathrm{M} / \mathrm{N} \cdot \mathrm{m}$ & $\mathrm{Fx} / \mathrm{N}$ & $\mathrm{Fy} / \mathrm{N}$ & $M / N . m$ & $\mathrm{Fx} / \mathrm{N}$ & $\mathrm{Fy} / \mathrm{N}$ & $M / N . m$ \\
\hline \multirow[t]{2}{*}{ Scheme 4} & Pie & $6.92 \mathrm{E}+05$ & $7.36 \mathrm{E}+05$ & 71.766 & $6.27 \mathrm{E}+06$ & $8.20 E+06$ & $3.95 \mathrm{E}+07$ & $3.49 \mathrm{E}+06$ & $4.02 E+06$ & 112.47 \\
\hline & $\begin{array}{l}\text { Bottom } \\
\text { of pier }\end{array}$ & $1.12 \mathrm{E}+06$ & $7.32 E+05$ & $1.04 \mathrm{E}+07$ & $6.43 E+06$ & $8.21 \mathrm{E}+06$ & $4.08 \mathrm{E}+07$ & $3.54 \mathrm{E}+06$ & $4.02 E+06$ & $4.47 \mathrm{E}+07$ \\
\hline \multirow[t]{2}{*}{ Scheme 5} & Pier top & $1.17 \mathrm{E}+06$ & $1.03 \mathrm{E}+06$ & 14.226 & $6.00 \mathrm{E}+06$ & $7.52 \mathrm{E}+06$ & $3.79 \mathrm{E}+07$ & $3.31 \mathrm{E}+06$ & $3.90 E+06$ & 8.9237 \\
\hline & $\begin{array}{l}\text { Bottom } \\
\text { of pier }\end{array}$ & $1.61 \mathrm{E}+06$ & $1.03 E+06$ & $1.60 \mathrm{E}+07$ & $6.19 E+06$ & $7.53 \mathrm{E}+06$ & $3.91 E+07$ & $3.40 E+06$ & $3.89 E+06$ & $4.27 \mathrm{E}+07$ \\
\hline
\end{tabular}

Table 3: Force comparison of seismic structure protection device

\begin{tabular}{llll}
\hline Scheme number & $\begin{array}{l}\text { The most dangerous force of lock-up } \\
\text { on No. 4 A pier of lock-up plant/N }\end{array}$ & $\begin{array}{l}\text { fluid viscous damper } \\
\text { The most dangerous force on } \\
\text { dampers on Pier 1 A/N }\end{array}$ & Damper stroke/cm \\
\hline Scheme 1 & & & 7.65 \\
Scheme 2 & $3.21 \mathrm{E}+06$ & $7.03 \mathrm{E}+05$ & 6.18 \\
Scheme 3 & & $1.17 \mathrm{E}+06$ & 6.87 \\
Scheme 4 & $3.49 \mathrm{E}+06$ & $6.92 \mathrm{E}+05$ & 6.13 \\
Scheme 5 & $3.31 \mathrm{E}+06$ & $1.17 \mathrm{E}+06$ & \\
\hline
\end{tabular}

Table 4: Reliability of uniform ground excitation tower system

\begin{tabular}{llll}
\hline Earthquake intensity & Calculation hypothesis & $\prod_{i=1}^{8} F_{i}$ & $\min _{i}\left[F_{i}\right]$ \\
\hline 7 degrees & Poisson hypothesis & 0.9999999978 & 0.9999999981 \\
& Markov assumption & 0.9999999980 & 0.9999999983 \\
8 degrees & Poisson hypothesis & 0.9996136215 & 0.9997440436 \\
& Markov assumption & 0.9996910478 & 0.9997955730 \\
9 degrees & Poisson hypothesis & 0.8055786548 & 0.9111391181 \\
& Markov assumption & 0.8613949908 & 0.9386888187 \\
\hline
\end{tabular}

\section{Discussions}

\subsection{Discussion on seismic response calculation results}

From Table $1 \sim$ Table 3, it can be seen that, the maximum horizontal thrust at the top of no. 3 rigid pier and at the top of six continuous piers in three schemes are: Scheme 1: 4.97E+06, 3.97E+07, Scheme 2: 8.04E+06, 2.31E+07, Scheme 3: 7.18E+06, 2.59E+07, Scheme 4: 6.27E+ 062, 0.50E+07, Scheme 5: 6.00E+06,2.78E+07.

Lock-up device makes it possible to transfer horizontal thrust between non-rigid pier and main beam, and significantly reduces the force of rigid pier and displacement of pier top, but it has no energy dissipation effect. 
Table 5: Reliability of bridge tower system considering traveling wave effect

\begin{tabular}{llll}
\hline $\begin{array}{l}\text { Earthquake } \\
\text { intensity }\end{array}$ & Calculation hypothesis & $\prod_{i=1}^{8} F_{i}$ & $\min _{i}\left[F_{i}\right]$ \\
\hline 7 degrees & Poisson hypothesis & 1.0000000000 & 1.0000000000 \\
& Markov assumption & 1.0000000000 & 1.0000000000 \\
8 degrees & Poisson hypothesis & 0.9999998774 & 0.9999999161 \\
& Markov assumption & 0.9999998867 & 0.9999999226 \\
& Poisson hypothesis & 0.9962287516 & 0.9981617009 \\
& Markov assumption & 0.9968205377 & 0.9984630482 \\
\hline
\end{tabular}

Table 6: Reliability of bridge tower system considering coherent effects

\begin{tabular}{llll}
\hline Earthquake intensity & Calculation hypothesis & $\prod_{i=1}^{8} F_{i}$ & $\min _{i}\left[F_{i}\right]$ \\
\hline 7 degrees & Poisson hypothesis & 1.0000000000 & 1.0000000000 \\
& Markov assumption & 1.0000000000 & 1.0000000000 \\
8 degrees & Poisson hypothesis & 0.9999988527 & 0.9999993469 \\
& Markov assumption & 0.9999989267 & 0.9999993903 \\
9 degrees & Poisson hypothesis & 0.9879487899 & 0.9949784587 \\
& Markov assumption & 0.9896085765 & 0.9957154261 \\
\hline
\end{tabular}



Figure 3: The change curve of $D=1.5 \mathrm{~m}$

The use of liquid viscous damper makes it possible to transfer horizontal thrust between non-rigid pier and main beam, but the effect of reducing the force and displacement of rigid pier is less obvious than that of lock-up device. From the maximum thrust sum, the liquid damper has a significant energy dissipation effect, and has a significant effect on improving the overall force of long-span bridge structure.

Due to the time-lag effect of liquid viscous dampers, the most unfavorable stress state of rigid-jointed piers and

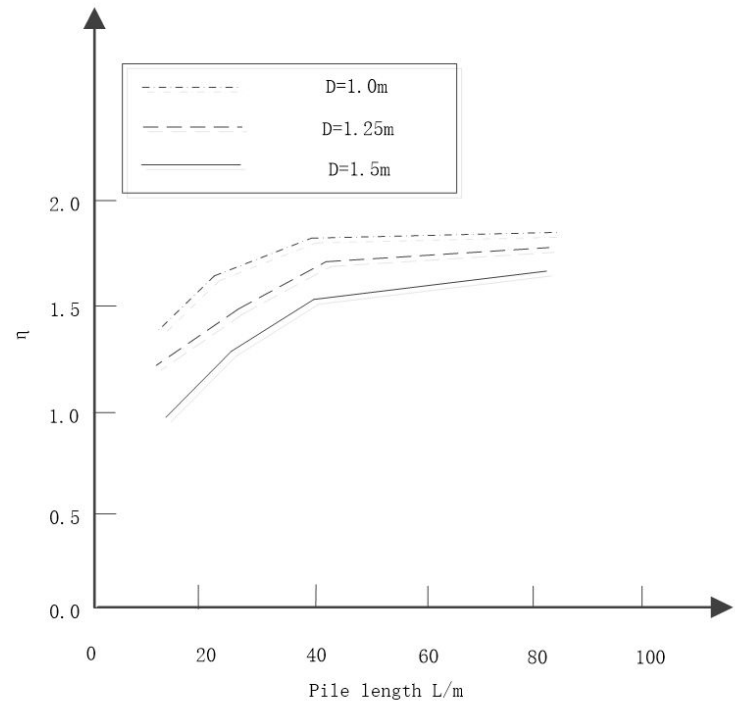

Figure 4: The change curve of $L=40 \mathrm{~m}$

non-rigid-jointed piers of long-span bridges appears, and there is a time-lag when the most unfavorable stress state appears in the use of the lock-up device.

The effect of reducing the most disadvantageous force of pier structure by increasing the damping value of damper is not obvious.

The combination of lock-up device and liquid viscous damper can give full play to the advantages of both structural protection devices.

Because of the use of lock-up device and liquid damper, long-span beam bridges can reduce the number of 
rigid joints between main girders and piers, thereby reducing the adverse effects of temperature effects on long-span bridge structures.

The lock-up device reduces the internal force on the rigid pier of the long-span bridge, and also increases the internal force of the non-rigid pier. But the internal force of rigid pier and non-rigid pier tends to be uniform, which is conducive to the residual bearing capacity of non-rigid pier.

Based on the above analysis, the 5 seismic design schemes for long-span bridges are feasible. The combination of lock-up device and liquid viscous damper in scheme 4 and scheme 5 can give full play to the advantages of the two structural protective devices and have the strongest seismic effect.

\subsection{Discussion on engineering example}

From Table 4, it can be seen that, with the increase of fortification intensity from 7 to 9, the calculated bridge structural reliability decreases from 0.99999978 to 0.8055786548. In Table 5, with the increase of fortification intensity, the reliability of the calculated bridge structure decreases correspondingly. Comparing tables 4 and 5 , the reliability of bridge structure is greater than that of uniform ground excitation when considering traveling wave effect. From Table 6, it can be seen that the traveling wave effect of earthquake ground motion causes the bridge structural response to become larger or smaller. The influence of reliability index on bridge structure is sometimes large and sometimes small. Comparing the results of Poisson-based Davenport method and Markov-based Vanmarcke method in Table 5 and Table 6, the reliability results of the two methods are not much different. The Poisson hypothesis has a slightly smaller result. It is concluded that for the proposed study method in most practical cases of seismic engineering research, it is not important to consider the Markov hypothesis. In most cases, this hypothesis may lead to non-conservative results.

\subsection{Analysis and discussion on influential factors of equivalent area of pile in improved layered Kerr spring model}

From Figure 2 Figure 4, it can be seen that equivalent area ratio $\eta$ of pile body in bridge structure is related to pile diameter $D$, pile length $L$ and vertical foundation coefficient at the bottom of pile $m 0$. The value may be less than 1.0 or greater than 1.0.
Under the condition of unchanged $m \mathrm{O}$ (or $L$ ), the equivalent area ratio $\eta$ increases with the increase of pile length $L$ (or $m 0$ ), but with the increase of $L$ (or $m 0$ ), the change $\eta$ becomes gentle.

When the pile length is constant, the equivalent area ratio of pile decreases with the increase of pile diameter.

The larger the equivalent area ratio of pile body, the greater the influence on the response of long-span bridge structure. Only when the equivalent area ratio of pile body is close to 1.0, the layered Winkler spring model can be used for seismic analysis, that is, it is not necessary to modify the section area of pile body of bridge structure.

\section{Conclusions}

The seismic process is a stochastic process. The time, place and size of the earthquake process are obviously uncertain. When an earthquake occurs, due to the influence of traveling wave effect, partial correlation effect and local site effect, the ground motion at each site varies with time and space. For long-span bridge structure, uniform ground motion input cannot control its seismic design. Considering the correlation of vibration at each point of seismic field, it is more reasonable to analyze the seismic response of bridge structure by multi-point excitation input method. Accurate simulation of seismic ground motion field is the basis and premise of structural seismic response analysis under multi-point excitation. In addition to the complexity of ground motion, it is difficult to obtain actual ground motion records in the simulation of seismic ground motion field. The existing seismic records, especially strong motion records, are not very rich. With the continuous accumulation of strong earthquake records, the model will be further improved to provide a more reasonable and practical model for structural random seismic response analysis.

In this paper, a new method for feasibility simulation study on aseismic structure design of long span bridges is proposed. 5 seismic isolation schemes for long-span bridge structures are designed. The lock-up device and liquid viscous damper are deployed in bridge structures. Numerical simulation of bridge structure is carried out by establishing calculation model and improved layered Kerr spring model. The responses of long-span bridges under seismic loading under 5 seismic isolation schemes are analyzed. Seismic performance of long-span bridges is tested by dynamic reliability analysis based on multi-point excitation equation of motion, response power spectrum and first exceeding failure criterion. In the proposed method, multipoint excitation equation of motion and response power 
spectrum analysis method based on probability analysis have great advantages over deterministic analysis method. It is based on the statistical characteristics of earthquake ground motion. The statistical seismic response is applied in long-span bridge structures to find out the response of structures. It provides a statistical measure of response without being controlled by an arbitrary input motion.

Experimental results show that the proposed five seismic isolation schemes are feasible, and the seismic effect of scheme 4 and scheme 5 is the strongest. The proposed method can effectively simulate the seismic behavior of long-span bridges.

\section{References}

[1] Zhang Y., Feng X., Hou S., Experimental Study of the Impact of Structural Joints on Seismic Failure Mechanism of Large Roller Compacted Concrete Arch Dam, J. Hydr. Eng., 2015, 46(10), 1222-1232.

[2] Lee S.B., Ahn S., Jangl.G., Simulation-Based Feasibility Study on the Wireless Charging Railway System with a Ferriteless Primary Module, IEEE Trans. Vehic. Technol., 2017, 66(2),10041010.

[3] Han H., Wang J., Meng X., Analysis of the Dynamic Response of a Long Span Bridge Using GPS/Accelerometer/Anemometer under Typhoon Loading, Eng. Struct., 2016,122,238-250.

[4] Gouder K., Zhao X., Limebeer D.J.N., Experimental Aerodynamic Control of a Long-Span Suspension Bridge Section Using Leading- and Trailing-Edge Control Surfaces, IEEE Trans. Contr. Syst. Technol., 2016, 24(4), 1441-1453.

[5] Pagnini L.C., Solari G., Stochastic Analysis of the Linear Equivalent Rsponse of Bridge piers with Aseismic devices, Earthq. Eng. Struct. Dyn., 2015, 28(5), 543-560.

[6] Mazzolani F.M., Piluso V., Plastic Design of Seismic Resistant Steel Frames, Earthq. Eng. Struct. Dyn., 2015, 26(2),167-191.

[7] Huang C.S., Yang Y.B., Lu L.Y., Dynamic Testing and System Identification of a Multi-span Highway Bridge, Earthq. Eng. Struct. Dyn., 2015, 28(8), 857-878.

[8] Attary N., Symans M., Nagarajaiah S., Numerical Simulations of a Highway Bridge Structure Employing Passive Negative Stiffness Device for Seismic Protection, Earthq. Eng. Struct. Dyn., 2015, 44(6), 973-995.
[9] Roy A.K., Ghosh A.A., Study on the Design Parameters of the Compliant LCD for Structural Vibration Control under Near Fault Earthquakes, J. Struct. Eng., 2015, 43(1), 10-19.

[10] Karamlou A., Bocchini P., Computation of Bridge Seismic Fragility by Large-Scale Simulation for Probabilistic Resilience Analysis, Earthq. Eng. Struct. Dyn., 2015, 44(12),1959-1978.

[11] Li Y., Conte J.P., Effects of Seismic Isolation on the Seismic Response of a California High-Speed Rail Prototype Bridge with Soil-structure and Track-structure Interactions, Earthq. Eng. Struct. Dyn., 2016, 45(15), 2415-2434.

[12] Zeng Q., Dimitrakopoulos E.G., Seismic Response Analysis of an Interacting Curved Bridge-train System under Frequent Earthquakes, Earthq. Eng. Struct. Dyn., 2016, 45(7), 1129-1148.

[13] Yang G., The Core Design of Open Loop Hall Current Sensor, Automat. Instrument., 2017.

[14] Wang S.B., Li X.M., Liu D., Concepts Association Mechanisms and Model Structures on Equipment System of Systems with Big Data, J. China Acad. Electr. Inform. Technol., 2016.

[15] Jiang L., Zhang Z., Analysis and Design of a Full-bridge CLL Resonant Converter with Double Resonant Tanks, J. Power Supply, 2017.

[16] Awati V.B., Naik S., Mahesh K.N., Multigrid Method for the Solution of Ehl Line Contact with Bio-Based Oils as Lubricants, Appl. Math. Nonlin. Sci., 2016, 1(2), 359-368.

[17] Pablo-Romero M.D.P., Pozo-Barajas R., Sanchez-Braza A., Analyzing the Effects of the Benchmark Local Initiatives of Covenant of Mayors Signatories, . Cleaner Prod., 2018, 176, 159-174.

[18] Gao W., Wang Y., Wang W., Shi L. The First Multiplication AtomBond Connectivity Index of Molecular Structures in Drugs, Saudi Pharmac. J., 2017, 25(4), 548-555.

[19] Liu Z., Peng W., Zare Y., Hui D., Rhee K.Y., Predicting the Electrical Conductivity in Polymer Carbon Nanotube Nanocomposites Based On the Volume Fractions and Resistances of the Nanoparticle, Interphase, and Tunneling Regions in Conductive Networks, Rsc. Adv., 2018, 8(34), 19001-19010.

[20] Butanda J.A., Málaga C., Plaza R.G., On the Stabilizing Effect of Chemotaxis On Bacterial Aggregation Patterns, Appl. Math. Nonlin. Sci., 2017, 2(1), 157-172.

[21] Prajapat K., Vyas A.K., Dhar S., Jain N.K., Hashim M., Choudhary G.L., Energy Input-Output Relationship of Soybean-Based Cropping Systems Under Different Nutrient Supply Options, J. Environm. Biol., 2018, 39(1), 93-101. 